\title{
A Satellite-Based Multi-Pollutant Index of Global Air Quality
}

\author{
Matthew J. Cooper, ${ }^{*}{ }^{\dagger}$ Randall V. Martin, ${ }^{\dagger \dagger}$ Aaron van Donkelaar, ${ }^{\dagger}$ Lok Lamsal, ${ }^{\S, \|}$ Michael Brauer, ${ }^{\perp}$ \\ and Jeffrey R. Brook \\ ${ }^{\dagger}$ Dalhousie University, Halifax Nova Scotia, Canada. B3H 3J5 \\ ${ }^{\ddagger}$ Harvard-Smithsonian Center for Astrophysics, Cambridge, Massachusetts, 02138, United States \\ ${ }^{\S}$ Universities Space Research Association, Columbia, Maryland 21044, United States \\ "Atmospheric Chemistry and Dynamics Laboratory, Earth Sciences Division, NASA Goddard Space Flight Center, Maryland 20771, \\ United States \\ ${ }^{\perp}$ University of British Columbia, Vancouver, British Columbia, Canada. V6T 1 Z3 \\ ${ }^{\ddagger}$ Air Quality Processes Research Section, Environment Canada, Toronto, Ontario, Canada.M6B 2S7
}

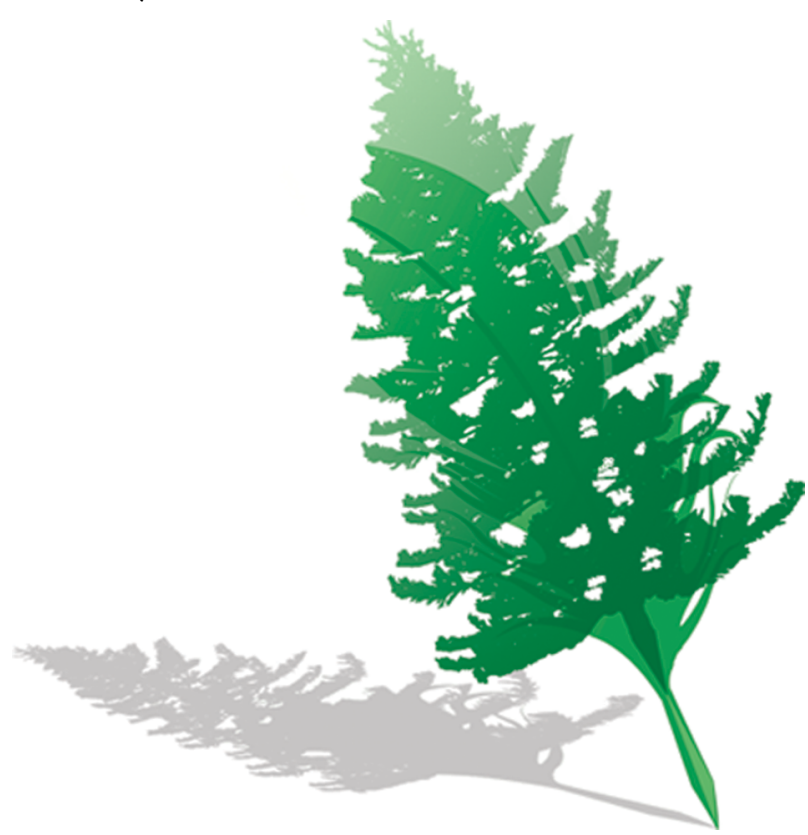

ir pollution is a major health hazard that is responsible for 1 millions of annual excess deaths worldwide. Simple indicators are useful for comparative studies and to assess trends over time. The development of global indicators has been impeded by the lack of ground-based observations in vast regions of the world. Recognition is growing of the need for a multipollutant approach to air quality to better represent human exposure. Here we introduce the prospect of a multipollutant air quality indicator based on observations from satellite remote sensing.

A variety of air pollution indices exist around the world. The air quality index of the U.S. Environmental Protection Agency at a given time and place is based on the highest concentration relative to the ambient air quality standard for $\mathrm{PM}_{2.5}, \mathrm{PM}_{10}, \mathrm{O}_{3}$, $\mathrm{NO}_{2}, \mathrm{SO}_{2}$, and $\mathrm{CO}$. The Canadian Air Quality Health Index is a multipollutant index based on the sum of $\mathrm{PM}_{2.5}, \mathrm{NO}_{2}$, and $\mathrm{O}_{3}$, weighted by their contribution to mortality in daily time-series study across Canadian cities. Gurjar et al. ${ }^{1}$ proposed a multipollutant index for megacities based on the sum of annual concentrations of total suspended particulates, $\mathrm{NO}_{2}$, and $\mathrm{SO}_{2}$, weighted by their deviation from World Health Organization
(WHO) guideline. These indices require observations from air pollution monitors. Yet most of the global population lives further than $100 \mathrm{~km}$ from monitors of even the most densely monitored pollutants, such as $\mathrm{PM}_{2.5}$.

Satellite remote sensing of air quality has advanced markedly over the past decade. The two pollutants for which global ground-level concentrations have been derived from satellite remote sensing are $\mathrm{PM}_{2.5}$ and $\mathrm{NO}_{2}$. Satellite-based estimates of $\mathrm{PM}_{2.5}$ and $\mathrm{NO}_{2}$ serve as a useful starting point for a global longterm multipollutant index. $\mathrm{PM}_{2.5}$ is a robust indicator of mortality and other adverse health effects. $\mathrm{NO}_{2}$ likely serves as a marker of other short-lived products of atmospheric combustion sources that increase the toxicity of the air pollution mixture. ${ }^{2}$ Thus we propose a satellite-based multipollutant index (SAT_MPI) in which we scale the local $\mathrm{PM}_{2.5}$ concentration by its ambient $\mathrm{NO}_{2}$ concentration:

$$
\text { SATMPI }=\frac{\mathrm{PM}_{2.5}}{\mathrm{AQG}_{\mathrm{PM} 2.5}}\left[1+\frac{\mathrm{NO}_{2}}{\mathrm{AQG}_{\mathrm{NO} 2}}\right]
$$

Following Gurjar et al. ${ }^{1}$ we reference $\mathrm{PM}_{2.5}$ concentrations to the WHO Air Quality Guideline (AQG) of $10 \mathrm{ug} / \mathrm{m}^{3}$ and $\mathrm{NO}_{2}$ to the AQG of $40 \mathrm{ug} / \mathrm{m}^{3}$. This equation represents a starting point for discussion. Several variations on this concept can be considered, including additional pollutants and area or population weighting for ranking of cities. Ground-level concentrations are taken from van Donkelaar et al. ${ }^{3}$ for $\mathrm{PM}_{2.5}$ and from Lamsal et al. ${ }^{4}$ for $\mathrm{NO}_{2}$. Both studies used a chemical transport model (GEOS-Chem, www.geos-chem.org) to relate satellite observations of the atmospheric column to groundlevel concentrations. The lack of observational estimates of global ground-level $\mathrm{O}_{3}$ is lamentable, however global mortality estimates for $\mathrm{PM}_{2.5}$ are 5 times larger than for $\mathrm{O}_{3}{ }^{5}$

Figure 1 shows the resultant SAT_MPI. Regional enhancements in the eastern U.S., Europe, northern India, and China reflect regional anthropogenic sources of $\mathrm{PM}_{2.5}$. Broad enhancements across northern Africa and the Middle East are driven by wind-blown mineral dust. Local enhancements over urban areas are due to the combination of $\mathrm{NO}_{2}$ and $\mathrm{PM}_{2.5}$. The bottom-left inset contains SAT_MPI for selected cities. Most of

Received: July 3, 2012

Accepted: July 9, 2012

Published: August 2, 2012 


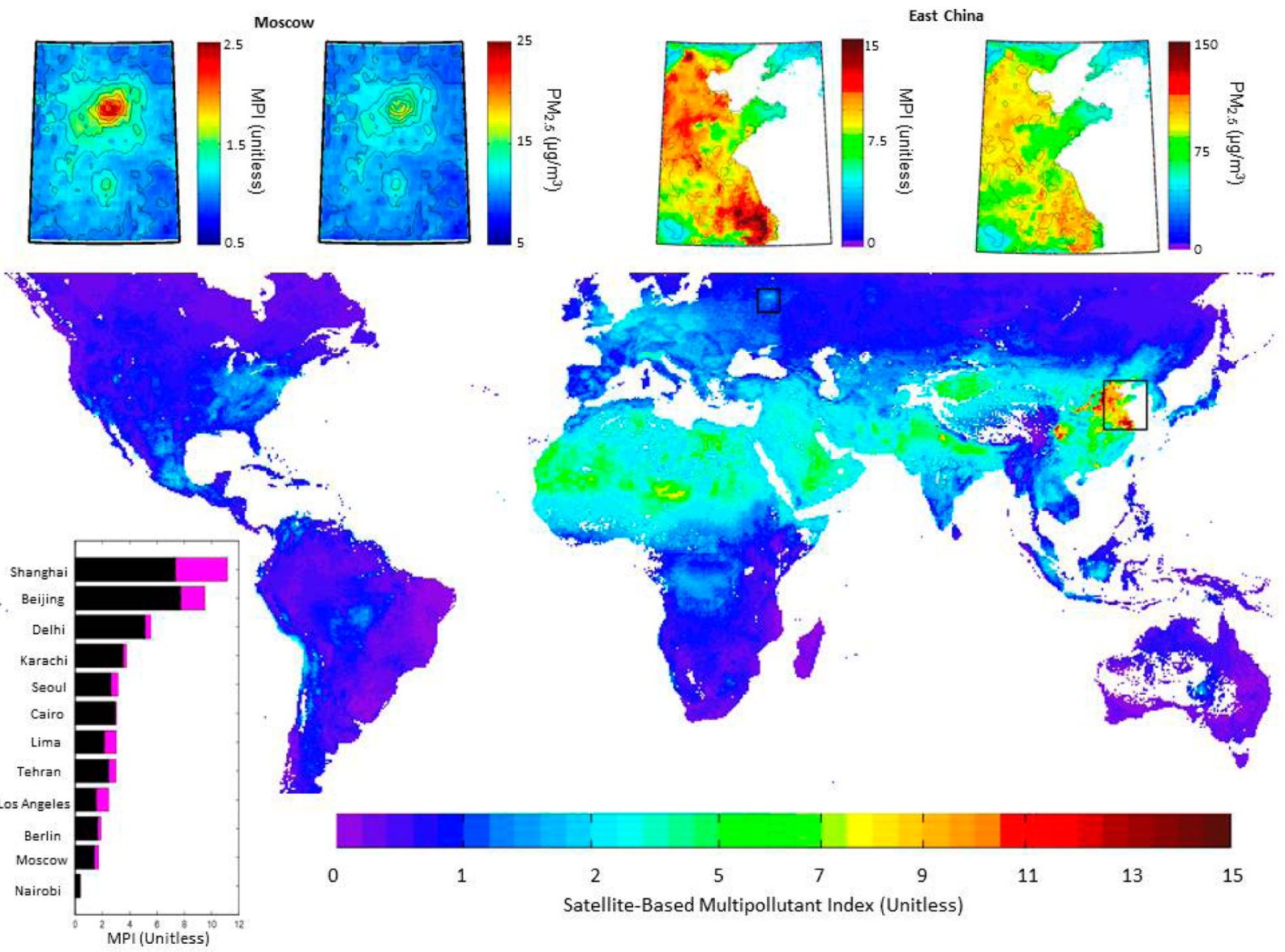

Figure 1. Annual mean satellite-based multipollutant index (SAT_MPI). The bottom left inset contains SAT_MPI for select cities (black indicates the contribution from $\mathrm{PM}_{2.5}$ and violet indicates the contribution from $\mathrm{NO}_{2}$ ). Top insets shows the index for Moscow and East China. Contours indicate population density. White space indicates water and missing data.

the effect is driven by $\mathrm{PM}_{2.5}$, however the addition of $\mathrm{NO}_{2}$ does change the relative ranking (e.g., Shanghai and Beijing). The top inset illustrates the spatial structure in the index, using Moscow and East China as examples. In both cases, the addition of $\mathrm{NO}_{2}$ indicates the influence of local combustion sources that increase the contrast between urban and rural locations. This index provides observational information about the worldwide distribution of pollution from local and global sources.

\section{AUTHOR INFORMATION}

\section{Corresponding Author}

*E-mail: cooperm2@dal.ca .

\section{Notes}

The authors declare no competing financial interest.

\section{ACKNOWLEDGMENTS}

We thank Rick Burnett from Health Canada for stimulating discussion. This work was supported by the Natural Sciences and Engineering Research Council (NSERC) of Canada.

\section{REFERENCES}

(1) Gurjar, B. R.; Butler, T. M.; Lawrence, M. G.; Lelieveld, J. Evaluation of emissions and air quality in megacities. Atmos. Environ. 2008, 42 (7), 1593-1606.

(2) Brook, J. R.; Burnett, R. T.; Dann, T. F.; Cakmak, S.; Goldberg, M. S.; Fan, X.; Wheeler, A. J. Further interpretation of the acute effect of nitrogen dioxide observed in Canadian time series studies. J. Exposure Sci. Environ. Epidemiol. 2007, 17, S36-S44.

(3) van Donkelaar, A.; Martin, R. V.; Brauer, M.; Kahn, R.; Levy, R.; Verduzco, C.; Villeneuve, P. J. Global estimates of ambient fine particulate matter concentrations from satellite-based aerosol optical depth: Development and application. Environ. Health Perspect. 2010, 118, 847-855, DOI: 10.1289/ehp.0901623.

(4) Lamsal, L. N.; Martin, R. V.; van Donkelaar, A.; Steinbacher, M.; Celarier, E. A.; Bucsela, E.; Dunlea, E. J.; Pinto, J. Ground-level nitrogen dioxide concentrations inferred from the satellite-borne ozone monitoring Instrument. J. Geophys. Res. 2008, 113, D16308 DOI: $10.1029 / 2007$ JD009235.

(5) Anenberg, S. C.; Horowitz, L. W.; Tong, D. Q.; West, J. J. An estimate of the global burden of anthropogenic ozone and fine particulate matter on premature human mortality using atmospheric modeling. Environ. Health Perspect. 2010, 118, (9). 